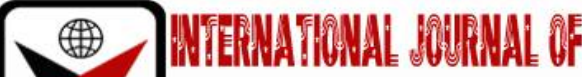

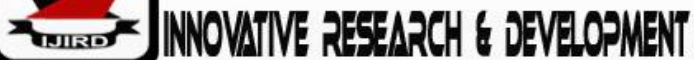

ISSN 2278 - 0211 (Online)

\section{Information Technology: A Tool for Effective SME Material Management Practices}

\begin{tabular}{c}
\hline Dr. Magaji Umar Ibrahim \\
Principal lecturer, Department of Metalwork Technology, \\
Federal College of Education (Technical) Gombe, Nigeria \\
Dr. Narimah B. Kasim \\
Associate Professor, Department of Construction Management, \\
University Tun Hussein Onn Malaysia (UTHM), Malaysia \\
Umar Gidado \\
Principal lecturer, Department of Building Technology \\
Federal College of Education (Technical) Gombe, Nigeria
\end{tabular}

\begin{abstract}
:
Nowadays, various strategies have been adopted to ensure reduction or elimination of waste in materials management practices in the construction industry for overall project performance. However, there are significant challenges related to Small and Medium Enterprises (SME) materials management practices, these challenges arise due to shortage of skills, practical know how, workers capability and financial difficulties in information technology (IT) adoption. Therefore, the aim of this study is to explore the potentials of IT as a tool for waste elimination or reduction in the Nigerian SME materials management practices for overall projects performance. The data were collected using structured questionnaires and administered to SME in the construction industry in the Northeast of Nigeria. The obtained data were analysed using Partial Least Squares Structural Equation Modelling (PLS-SEM) to determine significant level of IT in SME materials management practices. Outcome from the model of this study revealed that, IT adoption is significant with $R^{2}=0.622$ (62.2\%) which indicates that adoption of IT can improve SME materials management practices for overall projects performance.
\end{abstract}

Keywords: Small and medium enterprises, waste, information technology

\section{Introduction}

Small and Medium Enterprises (SME) in the Nigerian construction industry are significant contributor to the social, economic and environmental being of a country. SME's activity forecasts the general direction of most nation economy and for this reason SME's are often described as an engine of growth [1, 2]. SME construction sector is considered as one of the major value adding source to the development process of the Nigerian economy. [3] further stated that SME construction companies are strong base for rapid economic growth of Nigeria. This is achieved through job opportunities it created directly or indirectly to unskilled, semi-skilled and skilled labour. Further, [3] emphasised that any constraint to the success of this sector could have an overall effect on the growth of the economy of Nigeria.

\section{Small and Medium Enterprises in Nigerian Construction Industry}

Outwardly, SMEs in the construction industry are one of the oldest economic sectors globally which can be traced back too many years ago. Historically, it is a sector that involved in all activities associated with the repair and development of infrastructures. SME construction firms are a source of economic and social development. The sector has contributed significantly to Gross Domestic Product (GDP) of most developing nations and employer of about $20 \%$ of the Nigerian labour force [4]. However, current investigation shows that Nigeria's SME construction firms amongst other developing countries are still lagging behind in terms of performance in construction projects. This can be associated to the use of traditional method of materials management practices which generates various problems such as delay in projects, cost overrun, reworks, abandonment of projects and sometimes project termination. Traditional materials management practices have a lot of non-value adding activities (waste) which consumes time and efforts without added value to project $[5,6]$. This can hamper client-based oriented project value.

Prior researches have employed various methods to address the prevalent issue of materials management practices and its consequences on projects. One innovative approach used in this context is "Information Technology". This approach provides a continuous improvement in the manufacturing industry by reducing or eliminating various types of non-value activities [7-9]. While manufacturing had attained great results by the adoption and utilisation of IT, the construction sector, particularly SME still encounters problems resulting from non or low adoption of IT [1]. 
Considering the construction industry, project activities, [10] portrayed the sector as a fragmented with series of related but discrete activities. Often, face with issues of low productivity, low quality, time overrun, waste, inappropriate and poor materials management resulting in cost overrun. Of these, inappropriate or poor materials management is the major problem, as materials constituted a major cost part for any project and money is always of high importance. Poor materials management in construction sector has been a global issue of concerned, considering the fact that, ineffective management of materials has a severe effects on the three related inter-project values: time, money, and quality [11].

Projects are driven by a need to make sure the right quality and quantity of materials are appropriately specified in a timely manner, obtained at reasonable cost, and available when needed [12]. Although it is premised that projects are often to be delivered on time, within budget and quality, but yet these expected goals are not always realised. It is within this context that, the IT adoption in materials management is seen to have the potentials to improve the management of materials for effective projects performance. While, manufacturing industries have achieved great improvement by adoption and utilisation of IT by reducing the non-value activities (waste) within the production processes, the construction sector, particularly SME still encounters problems resulting from huge amounts of waste generation [13].

\section{Waste}

Activity that adds no value to a work or client or production is called "waste" (non-value activity). Waste has direct and indirect impacts on the project performance. Literature revealed the direct impact with respect to the project performance in terms of time [14]. The impacts of non-value adding activities on materials management includes additional waiting time, additional rework, additional materials, and additional labour for rework. [5] Identified reduced profit, diminished professional image, inter-organisational conflicts, loss of future work as effects of waste. Also, [15] identified several factors such as idle time, waiting time, transport time, and client dissatisfaction as consequences of ineffective materials management in the construction sector. Waste resulting from poor materials management practices can cause cost overrun which may resulted in project conflict.

Ineffective materials management practices have adverse impact on project cost, contractor's profit margin, project duration, and can be a possible source of dispute among parties involved in the project. Therefore, inefficiencies associated with conventional practices of materials management in SME often the root cause of project performance [2]. Therefore, conventional materials management practices have failed, which affects most SME construction firms project's performance in Nigeria directly or indirectly. [16] asserts that, reluctance to adopt new innovation of managing resources in this era of technologies pose a challenge in the face of SME's projects performance resulting to waste generations. The consequences of materials waste are enormous because materials account for about $55 \%$ to $65 \%$ of the project cost. This indicates need for new way of managing materials in order to avoid its generation and improve SME's performance. Fig. 1 presents the non-value activities resulting to waste generation.

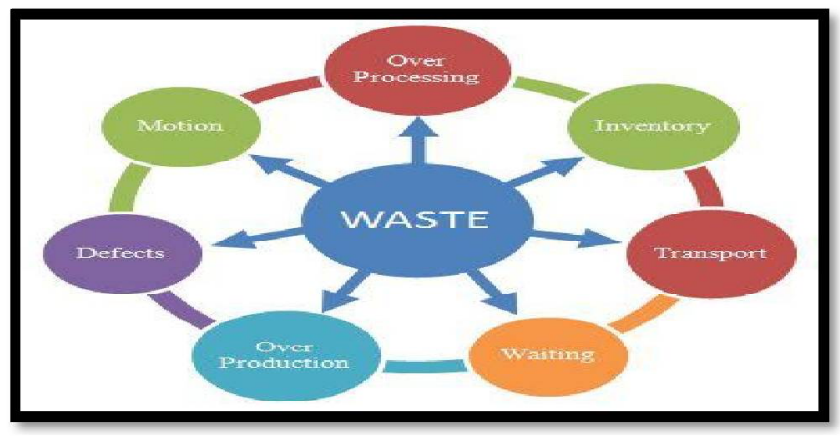

Figure 1: Non-Value Activities

Literature revealed that, materials wastages are evident in construction projects and are caused by several sources and causes [4, 11]. For example, [13] revealed six sources and 14 causes of materials waste in Turkish construction projects as shown in Table 1 (Appendix 1). Similarly, [17] revealed causes of waste in materials management in Nigerian projects as a result of poor supervision, design error, defective materials, unskilled labour, wrong quality materials, specification errors, poor storage, poor handling, poor material scheduling, poor material information, wrong suppliers advice and bulk purchased. They all have significant contribution to materials waste generation. Untrained labour, are among the most prevalent causes of waste generation in the Egyptian construction industry. Identification of these causes and application of relevant control techniques to minimize their occurrence is a step towards rejuvenating the SME's materials management practices which could enhance projects performance. Thus, it is imperative for SME construction firms to adopt information technology in order to reduce or eliminate non-value adding activities in materials management practices for the enhancement of materials management for productive SME's projects performance.

\section{Information Technology}

Information Technology (IT) is a diverse set of technological tools and applications that could create, disseminate, store, bring value-addition in day to day activities [18]. From the conceptual summary of IT definition shown in Fig. 2, literatures revealed that, processing, allocation, payment, ordering, locating, monitoring, and complaints can be handled using IT applications; for example, Global Positioning Systems (GPS) and Radio Frequency Identification Technology (RFID) are two important tracking and locating technologies used in construction. [19] indicated that the application of 
GPS not only provided direct time savings in the material-locating process, but it also reduced the number of lost items, work disruption and labor idle-time. In addition, it could improve standardisation and automation of locating process, route optimization, layout optimization, and data entry. [20] further stated that an automated material tracking system using radio frequency identification (RFID) technology combined with GPS technology requires minimal worker input and also could eliminate the deficiencies in the existing manual methods of identifying, tracking and locating of materials. Information Technologies could provide accurate, reliable and timely information to project players at the disperse projects locations which allow workers to access materials, tool and equipment which could reduce delay constraints resulting from the ineffectiveness of manual method of materials management practice. To buttress this, the current world of work has been impacted by IT revolution.

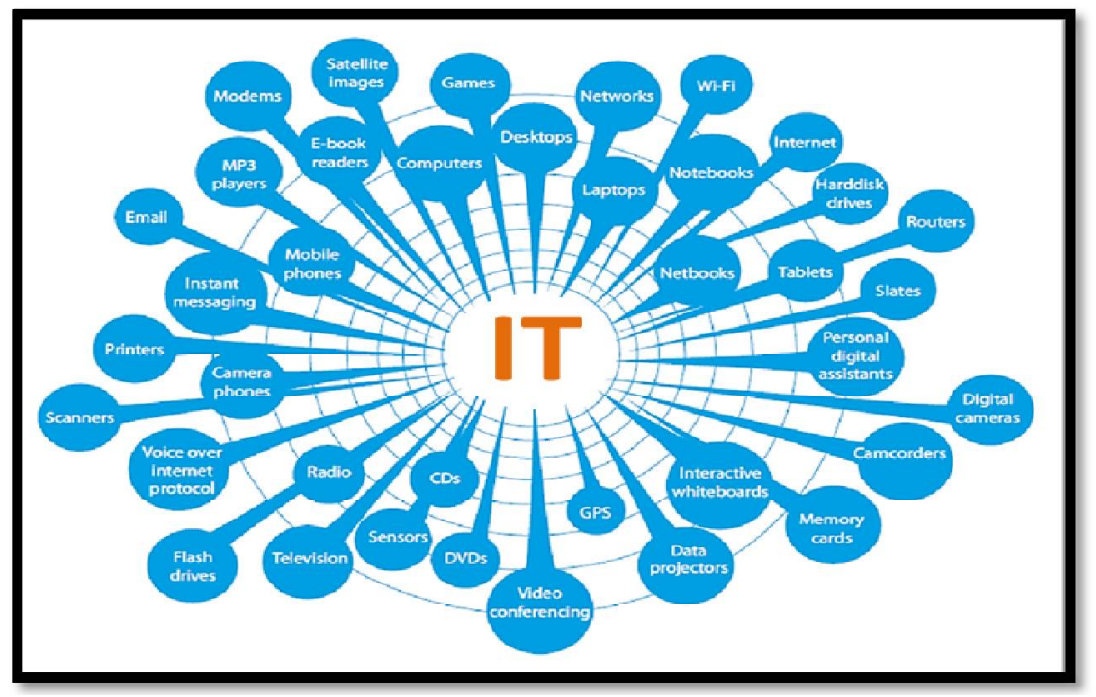

Figure 2: Conceptual Summary of ITS Definition

Nowadays, computers are as common as pen and paper for writing among people. This implies that there is an inversely proportional relationship between computer literacy and compositional literacy among the first global computer users. For many IT applications, especially communicating; computers are chosen over pen and paper because of their ability to store, duplicate, retain and retrieve information. Hence, IT integration could provide several significant benefits which include, improvement of materials management thereby enhancing and increasing the efficiency of the overall project performance. More so, connecting SME more easily and faster to outside SME domain locally or globally, thereby improving management activities and decreasing wastages in the material activities. Table 1 presents the summary of various IT applications that can be used in materials management practices.

\begin{tabular}{|c|c|c|}
\hline Facility & Description & Application \\
\hline Mobile Phone & $\begin{array}{l}\text { Is a portable telephone that has } \\
\text { access to a cellular radio system. } \\
\text { This enables the phone to take } \\
\text { calls, send texts, and access the } \\
\text { internet (and more!) without it } \\
\text { being physically attached to a } \\
\text { network using cables. }\end{array}$ & $\begin{array}{l}\text { - Organised -with important } \\
\text { features like documents, alarm, } \\
\text { calendars, memo, stop-watch: could } \\
\text { help SME become more organized. } \\
\text { - Constant contact- It help to } \\
\text { stay connected with Labourers, } \\
\text { customer, and the entire business } \\
\text { world. } \\
\text { - Daily Utilities - helps in } \\
\text { making bills payment, and } \\
\text { transportation booking } \\
\text { Faster } \\
\text { distribution }\end{array}$ \\
\hline Internet & $\begin{array}{l}\text { Is a global network of inter- } \\
\text { connected computers, where one } \\
\text { computer can be connected to } \\
\text { any other computer (or } \\
\text { computerized device) in any } \\
\text { portion of the world }\end{array}$ & $\begin{array}{l}\text { Helps to search for } \\
\text { information through various search } \\
\text { engines such as Google, Yahoo } \\
\text { Link parties involved } \\
\text { Transfer funds } \\
\text { Messages and project } \\
\text { documents can be sent as attached files } \\
\text { Provide platform for } \\
\text { information sharing among client and } \\
\text { suppliers }\end{array}$ \\
\hline
\end{tabular}




\begin{tabular}{|c|c|c|}
\hline Facility & Description & Application \\
\hline Facebook & $\begin{array}{l}\text { Facebook is a popular free social } \\
\text { networking website that allows } \\
\text { to upload information such as } \\
\text { advertisement, photos, messages } \\
\text { and keep in touch with and } \\
\text { customers }\end{array}$ & $\begin{array}{l}\text { Makes it possible for business } \\
\text { to be in the eyes through content } \\
\text { posting. } \\
\text { advertisement } \\
\text { Offers chance to put up } \\
\text { distribution } \\
\text { - Sharing information with } \\
\text { suppliers }\end{array}$ \\
\hline ATM & $\begin{array}{l}\text { An automated teller machine-Is } \\
\text { an electronic telecommunication } \\
\text { device that enables financial } \\
\text { transactions without human } \\
\text { cashier or bank teller. }\end{array}$ & $\begin{array}{ll}- & \text { Allow faster and easier } \\
\text { transaction } \\
\text { - } & \text { Saves time } \\
\text { - } & \text { Availability } 24 \mathrm{hrs} \\
- & \text { Easy to materials bill }\end{array}$ \\
\hline Whatsapp & $\begin{array}{l}\text { Is a cross-platform that allows } \\
\text { phones users to exchange text, } \\
\text { image, video and audio messages } \\
\text { for free }\end{array}$ & $\begin{array}{l}\text { Easy to send message } \\
\text { - } \quad \text { Provide group chart among } \\
\text { supplier, storekeeper, project manager, } \\
\text { workers and client. } \\
\text { - } \quad \text { Saves time and money } \\
\text { Easy to share location, photos } \\
\text { and status with parties involved }\end{array}$ \\
\hline
\end{tabular}

Table 1: Summary of IT Uses in Materials Management Continue

\section{Data and Methodology}

Data was collected using structured questionnaire survey. One hundred and sixty questionnaires were distributed among SME construction firms in the three states of the North-Eastern region of Nigeria. The collected data were analysed using Partial Least Squares Structural Equation Modelling (PLS-SEM).

\section{Results and Discussions}

In assessing the relationships of IT adoption and SME materials management performance using Partial Least Squares-Structural Equation Modelling (PLS-SEM) and a conceptual model was developed based on 32 manifest variables which were grouped into 4 factors (Exogenous latent variables), named as Effectiveness (ITA 1), Efficiency (ITA 2), Quality (ITA 3) and Speed (ITA 4). While Firm performance (FP) is regarded as endogenous latent variable (refer to Table 3). PLS analysis was carried out by calculating and assessing reliability and validity on the exogenous latent variables and this involves 2-step process [21], finally assessment of the structural model path coefficient [22].

\section{Model Evaluation}

The measurement model evaluation was aimed at evaluating the consistency and validity of the manifest variables. The evaluation of consistency is through individual manifest variables and reliability tests, while validity test is based on convergent and discriminant validity [23]. Therefore, evaluation of the measurement model is to determine the appropriateness of the manifest variables in order to ensure the manifest variables are fit and reliable in explaining the relationships between the indicators (manifest variables) and their corresponding constructs [24, 25]. In this regard, the measurement model was evaluated through assessing composite reliability (CR), convergent validity (CV), and average variance extracted (AVE). The manifest variables with outer loading 0.7 or higher are considered to be highly satisfactory [21], while variables with loading value of 0.5 are regarded as moderately satisfactory and variables with loading values below 0.5 should be eliminated [24]. However, [26] was on the view that, 0.4 should be the benchmark for loadings values. In another perspective, [21] suggested that manifest variable with loading value below the acceptable threshold should be reviewed before elimination, in order to ascertain if elimination of this manifest variable increases reliability or otherwise. Hence, for this study, the threshold value of 0.7 was considered for outer loadings as recommended by [24].

Stage two, parameter for consistency evaluations was evaluated through Cronbach's alpha or composite reliability (CR). Cronbach's alpha and CR explains how well a set of indicators appraises a latent construct. Although, CR is considered as a better measure of internal consistency compared to cronbach's alpha because it has a standardized manifest variable loading [25]. On the other hand, the threshold value for Cronbach's alpha should be 0.7 and higher, and for composite reliability the threshold of 0.7 is suggested as modest $[26,27]$ as to make significant judgement between IT and SME performance in relation to materials management. As implies that, the greater the threshold the higher significant result it will yield. For the variable's validity, the variables are assessed on convergent and discriminant validities [23]. The convergent validity is evaluated by Average Variance Extracted (AVE) test on the variables [28]. This determined the amount of variance captured in a latent variable from its relative manifest variables as a result of measurement errors. [29] and [30] stated that a minimum of 50\% variance from manifest variable should be achieved on latent variables. This implies that, 0.5 is the recommended threshold value for AVE. Discriminant validity (DV) is to assess the correlation amongst the exogenous variables for adequate discriminant validity, in this, the diagonal correlation value of the same 
exogenous variable should be greater than the off-diagonal values in the corresponding rows and columns [24, 26]. Further, [24] stated that, the square root of AVE in each latent variable can be used to establish the DV. Therefore, for each construct the AVE should be greater than the squares of the correlation between the constructs and all other constructs [25]. Based on the above criteria, measurement model was evaluated through iterative process in order to eliminate weak manifest variables which resulted in eliminating 11 manifest variables, Table 2 presents summary of the measurement model evaluation results.

\begin{tabular}{|c|c|c|c|c|}
\hline Constructs & Variables & Loading & AVE & CR \\
\hline \multirow[t]{5}{*}{ ITA1 } & EFFEC1 & 0.738 & 0.638 & 0.898 \\
\hline & EFFEC2 & 0.772 & & \\
\hline & EFFEC4 & 0.763 & & \\
\hline & EFFEC5 & 0.86 & & \\
\hline & EFFEC6 & 0.851 & & \\
\hline \multirow[t]{4}{*}{ ITA2 } & EFFI1 & 0.818 & 0.667 & 0.909 \\
\hline & EFFI2 & 0.825 & & \\
\hline & EFFI3 & 0.827 & & \\
\hline & EFFI4 & 0.801 & & \\
\hline \multirow[t]{5}{*}{ ITA3 } & QUAL2 & 0.734 & 0.689 & 0.917 \\
\hline & QUAL3 & 0.838 & & \\
\hline & QUAL4 & 0.843 & & \\
\hline & QUAL5 & 0.86 & & \\
\hline & QUAL6 & 0.868 & & \\
\hline \multirow[t]{5}{*}{ ITA4 } & SPEE1 & 0.719 & 0.667 & 0.890 \\
\hline & SPEE3 & 0.846 & & \\
\hline & SPEE4 & 0.865 & & \\
\hline & SPEE5 & 0.787 & & \\
\hline & SPEE6 & 0.857 & & \\
\hline \multirow[t]{3}{*}{ FFP } & FP1 & 0.855 & 0.649 & 0.902 \\
\hline & FP2 & 0.808 & & \\
\hline & FP3 & 0.789 & & \\
\hline
\end{tabular}

As shown in Table 2, all the retained manifest variables have achieved a satisfactory loading in accordance with the recommended threshold. The retained manifest variables are considered significant as their loadings values are $\geq 0.7$ [31, 32]. However, 11 weak manifest variables were dropped. Further, the results of the discriminant validity are presented in Table 3 which shows that, the manifest variables in each construct justified the validity of the model constructs [33]. This implies that, the discriminant validity of this study model is satisfactory, as suggested by [24] that, AVE of each construct should be greater than the squares of the correlation between the constructs and all other constructs.

\begin{tabular}{|c|c|c|c|c|c|}
\hline & ITA1 & ITA 2 & ITA 3 & ITA4 & FP \\
\hline ITA 1 & 0.817 & & & & \\
\hline ITA 2 & 0.490 & 0.799 & & & \\
\hline ITA 3 & 0.481 & 0.768 & 0.817 & & \\
\hline ITA 4 & 0.476 & 0.702 & 0.722 & 0.830 & \\
\hline FP & 0.423 & 0.634 & 0.0551 & 0.633 & 0.806 \\
\hline \multicolumn{7}{|c|}{ Table 3: Discriminant Validity } \\
\hline
\end{tabular}

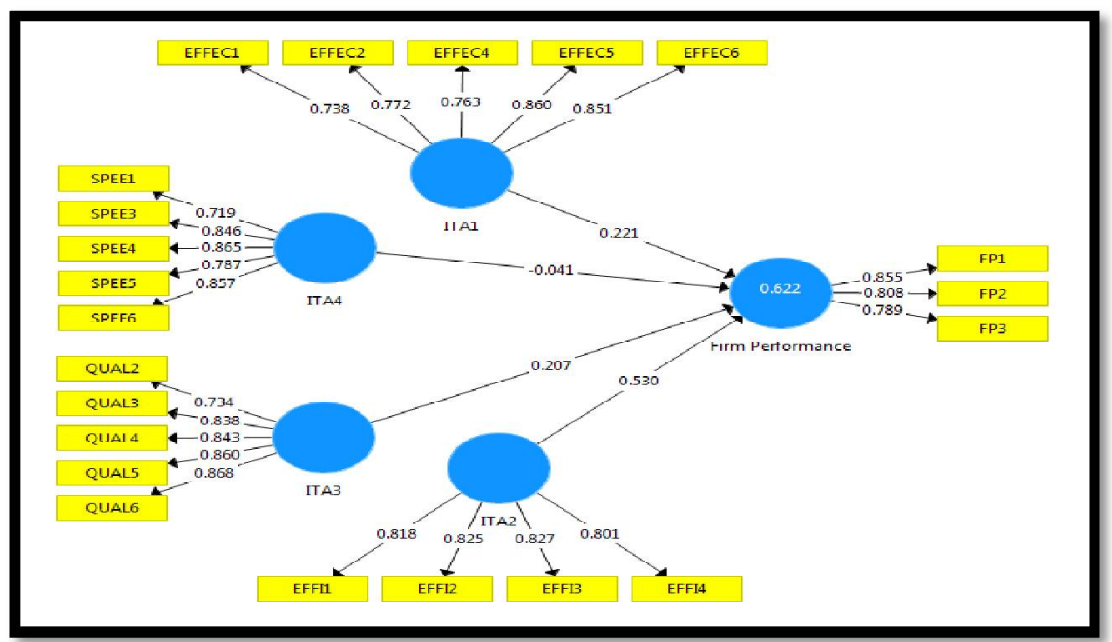

Figure 3: Relationships between IT and Firm Performance 


\section{Conclusion}

The purpose of this paper is to identify the structural relationships between information technology adoption and SME towards sustainable materials management for overall projects performance. The results revealed that Efficiency, Effectiveness and Quality constructs are found to have significant relationship with SME's IT adoption, with effectiveness as having strong effects on the SME's IT adoption. The results also revealed that, Speed construct has insignificant relationships with SME's adoption of IT at $\beta=0.57$. Although, the sum of the effects of the exogenous constructs indicates that, all the factors are highly correlated towards IT adoption for the Nigerian SMEs at R2 0.622 (62.2\%). This indicates that, SMEs and SME stakeholders in Nigeria should not overlook these factors in trying to design strategy for influencing IT adoption by SME construction firms and construction industry at large.

In view of the findings, this study recommends that all stakeholder in the SME in the construction industry should consider the use of IT in materials management for overall projects performance in order to supports a competitive economy as well as promote spatial economic development consequently, increase self-employment opportunities among nation unemployed youths. Furthermore, government should promote the use of IT aiming at qualitative and sustainable projects.

\section{References}

i. M. U. Ibrahim and N. B. Kasim, "Information Technology as a Viable Strategy for Improving Material Management Practices in SME Construction Projects Performance," International Journal of Innovative Research and Development, vol. 6, 2017.

ii. E. Equere and L. C. Tang, "Dearth of automation: the consequences in Nigeria construction industry," Autom. Constr, vol. 14, pp. 500-511, 2010.

iii. C. Nwachukwu and F. Emoh, "A systems approach in analysing material constraining factors to construction project management success in Nigeria," Interdisciplinary Journal of Contemporary Research in Business, vol. 2, pp. 90$104,2010$.

iv. A. Wahab and A. Lawal, "An evaluation of waste control measures in construction industry in Nigeria," African Journal of Environmental Science and Technology, vol. 5, pp. 246-254, 2011.

v. P. E. Love, "Influence of project type and procurement method on rework costs in building construction projects," Journal of construction engineering and management, vol. 128, pp. 18-29, 2002.

vi. A. Aiyetan, "Causes of rework on building construction projects in Nigeria," Interim: Interdisciplinary Journal, vol. 12, pp. 1-15, 2013.

vii. T. H. Davenport, Process innovation: reengineering work through information technology: Harvard Business Press, 1993.

viii. H. O. Agrawal, "An Approach to Business Strategy," in Handbook of Research on Promotional Strategies and Consumer Influence in the Service Sector, ed: IGI Global, 2016, pp. 154-182.

ix. S. Ü. O. Fırat, C. Ağlan, Z. T. Kalender, İ. Ülkü, G. Bayram, and M. Erdem, "Lean Thinking via Business Intelligence Technologies and Innovation Process," in Handbook of Research on Driving Competitive Advantage through Sustainable, Lean, and Disruptive Innovation, ed: IGI Global, 2016, pp. 59-85.

x. P. E. Love and D. J. Edwards, "Forensic project management: The underlying causes of rework in construction projects," Civil Engineering and Environmental Systems, vol. 21, pp. 207-228, 2004.

xi. M. M. Marzouk and T. I. El-Rasas, "Analyzing delay causes in Egyptian construction projects," Journal of advanced research, vol. 5, pp. 49-55, 2014.

xii. G. Polat and G. Ballard, "Waste in Turkish construction: need for lean construction techniques," in Proceedings of the 12th Annual Conference of the International Group for Lean Construction IGLC-12, August, Denmark, 2004, pp. 488-501.

xiii. E. Palaneeswaran, "Reducing rework to enhance project performance levels," in Proceedings of the One Day Seminar on Recent Developments in Project Management in Hong Kong. Hong Kong: Centre for Infrastructure and Construction Industry Development, 2006.

xiv. J. L. Burati Jr, J. J. Farrington, and W. B. Ledbetter, "Causes of quality deviations in design and construction," Journal of construction engineering and management, vol. 118, pp. 34-49, 1992.

xv. M. Naala, N. Nordin, and W. Omar, "Innovation Capability and Firm Performance Relationship: A Study of PlsStructural Equation Modeling (Pls-Sem)," International Journal of Organization \& Business Excellence, vol. 2, pp. 39-50, 2017.

xvi. O. J. Oladiran, "Causes and Minimization Techniques of Materials Waste in Nigerian Construction Process," in Fifth International Conference on Construction in the 21st Century (CITC-V); Collaboration and Integration in Engineering, Management and Technology, 2009, pp. 20-22.

xvii. Y. Pardhasaradhi and V. N. Rao, "Women Empowerment: Information Technology as a Critical Input," Indian Journal of Public Administration, vol. 60, pp. 515-526, 2014.

xviii. N. Kasim, "ICT implementation for materials management in construction projects: case studies," Journal of Construction Engineering and Project Management, vol. 1, pp. 31-36, 2011.

xix. E. Ergen, B. Akinci, and R. Sacks, "Tracking and locating components in a precast storage yard utilizing radio frequency identification technology and GPS," Automation in construction, vol. 16, pp. 354-367, 2007.

xx. J. Henseler, C. M. Ringle, and R. R. Sinkovics, "The use of partial least squares path modeling in international marketing," in New challenges to international marketing, ed: Emerald Group Publishing Limited, 2009, pp. 277319. 
xxi. V. E. Vinzi, W. W. Chin, J. Henseler, and H. Wang, Handbook of partial least squares: Concepts, methods and applications. Verlag, Berlin: Springer Science \& Business Media, 2010.

xxii. J. F. Hair, M. Sarstedt, T. M. Pieper, and C. M. Ringle, "The use of partial least squares structural equation modeling in strategic management research: a review of past practices and recommendations for future applications," Long range planning, vol. 45, pp. 320-340, 2012.

xxiii. J. F. Hair Jr, G. T. M. Hult, C. Ringle, and M. Sarstedt, A primer on partial least squares structural equation modeling (PLS-SEM): Sage Publications, 2016.

xxiv. K. K.-K. Wong, "Partial least squares structural equation modeling (PLS-SEM) techniques using SmartPLS," Marketing Bulletin, vol. 24, pp. 1-32, 2013.

xxv. J. Hulland, "Use of partial least squares (PLS) in strategic management research: A review of four recent studies," Strategic management journal, pp. 195-204, 1999.

xxvi. J. F. Hair, M. Sarstedt, C. M. Ringle, and J. A. Mena, "An assessment of the use of partial least squares structural equation modeling in marketing research," Journal of the academy of marketing science, vol. 40, pp. 414-433, 2012.

xxvii. C. Fornell and D. F. Larcker, "Evaluating structural equation models with unobservable variables and measurement error," Journal of marketing research, pp. 39-50, 1981.

xxviii. W. W. Chin, "The partial least squares approach to structural equation modeling," Modern methods for business research, vol. 295, pp. 295-336, 1998.

xxix. J. Hair, J. Hair, C. L. Hollingsworth, C. L. Hollingsworth, A. B. Randolph, A. B. Randolph, et al., "An updated and expanded assessment of PLS-SEM in information systems research," Industrial Management \& Data Systems, vol. 117, pp. 442-458, 2017.

xxx. S. Akter, J. D'Ambra, and P. Ray, "An evaluation of PLS based complex models: the roles of power analysis, predictive relevance and GoF index," 2011.

xxxi. M. Sarstedt, J. Henseler, and C. M. Ringle, "Multigroup analysis in partial least squares (PLS) path modeling: Alternative methods and empirical results," in Measurement and research methods in international marketing, ed: Emerald Group Publishing Limited, 2011, pp. 195-218.

xxxii. C. Annamalai and T. Ramayah, "Does the organizational culture act as a moderator in Indian enterprise resource planning (ERP) projects? An empirical study," Journal of Manufacturing Technology Management, vol. 24, pp. 555587, 2013.

xxxiii. R. P. Bagozzi and Y. Yi, "On the evaluation of structural equation models," Journal of the academy of marketing science, vol. 16, pp. 74-94, 1988.

xxxiv. J. Cohen, "Statistical power analysis for the behavioral sciences. Hilsdale," NJ: Lawrence Earlbaum Associates, vol. 2, 1988. 